Practical Limits to the European Harmonisation of Waste Policies: the Case of Italy

\section{Top-down Standards versus Bottom-up Learning Processes}

\begin{abstract}
Wie das Beispiel Hausmüllpolitik zeigt, ist die Ähnlichkeit der Umweltpolitiken in Europa oft nur oberflächlich; in der Praxis bestimmen weiterhin nationale Unterschiede das Bild. Hieran ändert auch eine von der EU "von oben" beschlossene Harmonisierung der Standards wenig, solange der für die Umsetzung zentrale Implementationsprozeß weiterhin national kontrolliert wird. Für eine erfolgreiche Weiterentwicklung der Politik muß daher diese "black box" geöffnet werden. Insbesondere ist eine genaue Analyse der Akteure und ihrer Interaktion nołwendig. Dabei zeigt sich, daß die Diversität der nationalen Lösungen auch Vorzüge mit sich bringt, die nur genułzł werden können, wenn die Koordination der Politiken den Spielraum der lokalen Akteure berïcksichtigt.
\end{abstract}

A

Von Antonio Massarutto $\mathrm{t}$ a first glance, it might seem that European countries share many similarities with respect to the organization of waste management policies, if not in the quality of environmental policy objectives and the level of their achievement. For example there exists a national legislation that determines general objectives (e.g. priority ladders, self-sufficiency) and performance standards (e.g. emission limits, technical requirements of landfills, minimum recycling rates for packaging materials). This is increasingly subsumed into an European set of standards and rules. Furthermore in all countries, legislative standards are translated into a definite policy through the planning process that is usually carried on at the regional level - though the definition of ",region“ is not always the same. Regional plans normally deal with recycling targets, number and typology of disposal facilities, measures for handling certain waste flows; municipalities and other waste producers have to arrange their disposal activities according to targets and limitations set up in the plan and so on.

These broad similarities might induce the false perception that waste management policies work more or less in the same way in different countries, in a rather ,top-down " manner; the decisive input would be the legislative one, therefore differences in performanice would depend largely on the different set of environmental targets that each country pursues. An indirect consequence of this reasoning is that if it is recognized that asymme- tric waste management policies might cause undesired spill-over effects among countries, the solution might be to search for an harmonisation of environmental policy targets inspired by new common legislation (e.g. arising from the $\mathrm{EU}$ level). Each national system, as a „black box" working in a largely similar way, would achieve autonomously these common targets.

As we try to show in this contribution, however, this might not be the case. Despite superficial similarities, institutional systems for managing waste differ very much among countries, and this difference is better appreciated through a positive analysis of the decision-making system.

If we compare European countries, we realise that, while actors are broadly the same everywhere, the relations between them, and especially the ,division of labour" among them, are very different. In this sense, the same normative inputs (e.g. the imposition of a common standard for, say, plastics recycling or sulphur emissions) might lead to completely different outputs in terms of achieved targets of environmental policy. In fact, the strategy adopted by the European Commission has been to search for a gradual compromise around harmonised policy targets, therefore acting basically through the legislative input. With a series of directives starting from the $70 \mathrm{~s}$, the EC has increasingly tried to set up a common legislative framework to be adopted by member countries, and basically involving minimum standards to achieve - and later on maximum standards aimed at avoiding cross-national externali- ties. Yet after more than 20 years of common waste management policy, a convergence of national trajectories is largely unachieved.

\section{Why convergence is unachieved}

A first explanation of this fact is the relative strength of national enforcement systems with respect to waste generation, collection and disposal. The main point is that, first, each national system faces different structural and institutional problems in setting up an effective monitoring and enforcement system; second, and even more important, enforcement is normally controlled at the local level, and is typically asymmetric, in the sense that local operators, well-rooted in the territory, often in public hands, usually enjoy a better treatment than „foreign“ operators; due to this asymmetry, the local policy arena remains largely impermeable to the standards imposed from upper levels of the administration; large firms with better technologies might face difficulty in the penetration of the market that remains dominated by local operators with poor quality standards but more able to "capture" regulation at the enforcement stage or to adapt and postpone the achievement of general targets. This consideration leads to a very clear policy implication: instead of concentrating attention on the improvement of legislative targets, policymakers should concentrate on the bottleneck of control and enforcement and guarantee at least a homogeneity of treatment among different waste management operators.

A second, and perhaps broader, explanation, considers more explicitly the implementation process, starting from the consideration that each local system has largely specific aims with respect to waste management objectives; each administrative level having a stake in the implementation process normally enjoys an ineliminable degree of autonomy and degrees of freedom. Each „local" system, therefore, is able to avoid and/or adapt nationally-imposed targets if these are posing an excessive stress on the system, or simply if the local system can go on with its own resources - eventually with some ,protectionism", e.g. bans on import of waste in order to maintain landfill capacity for a longer time.

In other words, despite the fact that waste management is formally designed in the institutional setting as a hierarchically-dominated top-down decision process, real institutional organisation - that is, who actually takes relevant decisions and enacts them - works in a much more decen- 
tralised way, in a bottom-up fashion. Attention must be concentrated on the real functioning of the waste management system (WMS), intended as a network of actors with mutual relations and usually conflicting targets, whose ,collective action" is ultimately the engine of policy definition and implementation.

In this perspective, a far more relevant issue becomes to analyse the structure of these relations within the whole WMS, together with the dynamics of co-operation and collective learning, together with the balance of costs and benefits between different areas, and between local, regional and national levels. National, and a-fortiori European policies cannot be conceived as a purely impositive administrative decision; and better results are probably achieved if policymakers concentrate on the aim of creating a setting that encourages local actors to spontaneously behave in a certain manner, rather than trying to impose targets from outside without - a true capacity to have them implemented.

\section{- From a normative to a positive analysis}

If we analyse more in deep the functioning of each country, we might realize that the WMS results from the interaction of a number of actors. Each of them has only a limited set of resources and available actions, has an imperfect knowledge, has an inherited power that depends on the role that it has played in the system in the past. The key idea is that environmental regulation does not fall onto a ,black box": rather, it is converted into a definite policy through many steps, and each step is constrained by other concurrent problems:

the ned to provide a good service to the city (rapidly eliminate waste from the streets) might conflict with the target of improved recycling rates;

the need to control expenditure for public services and reach efficiency might contrast with the requirement of an improved environmental quality of waste management;

the effectiveness and efficiency of waste management operation depends crucially on the quality of inputs (technologies, specialised services etc) that the operator acquires on the market, and therefore the degree of competitiveness in the industrial organisation chain.

Mutual influences among actors ultimately determine the existing equilibrium and the dynamic evolution of the system; patterns of conflict or co-operation among them highly influence the way the system works, the pursuit of priorities, and vicious or virtuous circles that accelerate or prevent the system's evolution.

Among the most important aspects that might influence the structure of the WMS, we can mention the dialectical relation between local and upper levels, the division of responsibilities between the public and the private sector, the eventual presence of an alliance between operators and manufacturers in support of certain technologies (e.g. waste-to-energy), the pressure of public opinion and of environmental movements on the political and on the productive system. According to the different mix of these and other variables, we can detect quite a wide number of waste management systems. Actually, it is not correct to consider the waste problem as affecting all areas in the same way and degree. Right to the contrary, within each nation and even within each regional area problems might differ very much and locally-perceived priorities can differ as well. Just one example for this:

Shortage of disposal sites, for example, is not the same everywhere. UK is an example, but also in many areas of France, Italy and Greece it is usually not so difficult to individuate areas for building new landfills. Reasons for "shortage" are also different: in some cases - possibly a very few ones - the problem is physical shortage; in most other cases, the problem is the unreadiness of the social and economic environment to bear the external costs ,close to their backyards"; again, the social conflict is managed in many different ways, and European countries

\section{Städtische Nutzung und Verkehr}

ist das Thema des Informationsdienstes Ökologisches Wirtschaften $5-6 / 99$

Konsum zwischen Ethik und Erlebnis

\section{ist das Thema des \\ Informationsdienstes \\ Ökologisches Wirtschaften $1 / 2000$}

Wenn Sie potentielle Beiträge haben, wenden Sie sich bitte an die Redaktion. show us plenty of examples of successful relations allowing a sound long-term acceptability of landfilling practices, as well as cases where the „not in my backyard"-syndrome has been so acute that even building a very small landfill for inerts proved to be impossible.

\section{A panorama of approaches}

„Better an egg today than a hen tomorrow", says an universal proverb. In fact, being waste management - and particularly end-of-pipe disposal with hard technology - typically a sunk-cost industry, policymakers and operators are always facing the issue whether solving short-term problems with maybe non-optimal technologies in the long run, or put a bet on the future capacity to solve problems in a more efficient way, but being at risk of postponing the solutions of today's problems.

Waste disposal planning in the past has often tried to implement a „one-best-way“ solution based on the centralisation at the regional/provincial scale of treatment operations, in order to reach economies of scale.

In fact, the effectiveness of this strategy has not been the same everywhere. It is influenced by

- the relative strength of different layers of government (inherited by history);

the tradition of co-operation among nearby municipalities (and especially among chieftowns and surrounding areas) and

the higher or lower propensity to delegate operation to specialised organisations - or even private firms.

The final equilibrium has been very different. In some cases - e.g. Germany, Netherlands - the transfer of responsibility has been almost total: disposal sites are controlled by inter-municipal or provincial bodies, and municipalities are more or less obliged to use these plants. In other cases - e.g. France - a similar result has been reached through the intermediation of private firms, even if each municipality formally continues to be autonomous. In still other cases - e.g. Italy - regional plans have never been implemented, at least not fully, municipalities continue to rely on themselves and the plan is, in fact, much more concentrated on the governing of short-term trade of waste between areas rather than on the provision of collective facilities. However, this might not turn as a disadvantage for the Italian system. While regional efforts aimed at imposing a common strategy have failed, local systems have been forced to look for 
solutions themselves, and this has often led to innovative and original solutions. Communal associations reaching 60-70 percent of recycling targets, for example, are not so infrequent; and their typical way of organising the system avoids centralised operations and integrated firms; rather, it involves specialisation (e.g. firms specialised in the processing of definite waste categories) and a highly dynamic division of labour between small and medium firms.

\section{- A follower's problem}

Given these circumstances, a very difficult choice has to be made, especially by countries like Italy or Greece, where landfilling is still dominant:

On one side, there is the concrete option of ,stage-skipping", that is: avoiding the need of large and centralised sunk-cost facilities by moving directly from the „,everything in landfill“ strategy to very high and ambitious recycling rates.

On the other side, this strategy might reveal to be very risky, particularly for areas that are experiencing waste-related stress, or are still using environmental unfriendly solutions. At the beginning of the $90 \mathrm{~s}$, for example, many cities in Northern Italy have seen disposal costs rising dramatically (from 20-30 Euro / ton to even ten times more), either because of the rent they had to pay to the owners of nearby plants, or because of the transport costs necessary for reaching cheaper facilities. At the same time, in Southern Italy and Greece, while technicians discuss about the potential of stage-skipping, bad quality landfills - and even uncontrolled dumping still remain the dominant practice.

\section{Conclusion}

In the end, our analysis shows that waste management police is - and largely continues to be - a matter of local politics and management, increasingly being affected by common regulations. While the aim of these regulations in the past has been a gradual improvement of minimum standards, in more recent times the issue of reciprocal externalities has entered the political agenda. In this sense, the problem is not simply that of ensuring a minimum common standard, but also that of preventing strategies carried on in a local context from hampering waste management policies in other areas, e. g. by international transfers of packaging waste.

As a result, the waste management policy has rapidly changed its aims: from a purely ,,regula- tory" policy - where the object of control was the compliance with the law - to an increasingly „proactive" policy, in which many actors are in charge of implementation, and strategies must necessarily arise independently from a wide number of subjects, beyond the capacity of control of the public administration.

As the previous section shows, implementing a waste management policy - especially when this is intended as an ,active“ strategy, aiming at governing materials flows rather than at a purely ,end-of-pipe“ approach - is not simply a matter of rules and enforcement.

Therefore, it might be naive to retain that asymmetries in the environmental performance of $\mathrm{EU}$ countries is simply a matter of, first, less ambitious policy targets and, second, poor enforcement of existing rules. In other words, it is simplistic to think that the inefficiencies and ineffectiveness of the monitoring and sanctioning system is the guilty, and that it could be sufficient to replace it with an ,European enforcement agency" or anything similar in order to achieve better performances.

Waste management is a typically ,loosely-coupled" decision-making system, and we cannot reduce it to a simple and mechanical hierarchical organisation working on the base of command and control. Improving waste management practices - especially if this means a gradual shift from the traditional ,end-of-pipe“ strategy to one concentrated on the optimisation of materials flows - is not simply a matter of environmental policy: rather, it requires a coordinated policy action on the industrial systems. In each country, the structure of the WMS is likely to react in very different ways to policy measures. Therefore an environmental and industrial policy in this sector should start from a careful consideration of the structure of the WMS and of the dynamic relations that govern its evolution, in order to maximise the potential for virtuous circles and minimise the vicious ones.

\section{Der Autor}

Antonio Massarutto ist Forscher am Dipartimento di scienze economiche, Università di Udine and am IEFE, Università Bocconi, Mailand.

Kontakt: IEFE, Universita L. Bocconi, Viale Filipetti 9, I-20122 Milano, Tel. 0039-25836-3820, Fax 3890, E-mail: amassaru@mailerl.sm.uni-bocconi.it

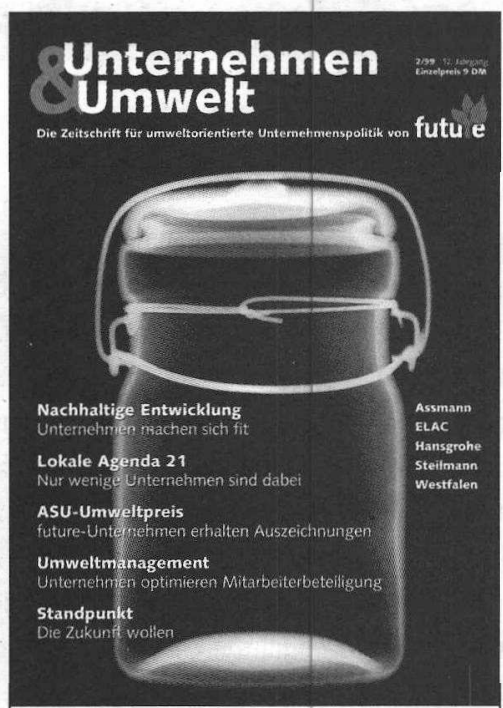

Unternehmen \& Umwelt

- ist die Zeitschrift für umweltorientierte Unternehmenspolitik von future e.V.,

- berichtet über den neuesten Stand zum betrieblichen Umweltmanagement in Theorie und Praxis,

- bietet vier Mal im Jahr ein Schwerpunktthema, Unternehmensbeispiele, Literaturund Veranstaltungshinweise und aktuelle future-Nachrichten.

Zum Beispiel Heft 2/99:

Nachhaltigkeit

- Nachhaltige Entwicklung: Unternehmen machen sich fit.

- Lokale Agenda 21: Nur wenige Unternehmen sind dabei.

- Betrieblicher Umweltschutz: Assman, ELAC, Hansgrohe, Steilmann.

- Umweltmanagement: Unternehmen optimieren die Mitarbeiterbeteiligung.

Fordern Sie Ihr kostenloses Probeexemplar an:

Fon: 0234 - $97995-13$ Fax: $0234-97995$ - 14

future e.V. Büro Bochum Am Varenholt 123 44797 Bochum email: future@umis.de future 
(c) 20I0 Authors; licensee IÖW and oekom verlag. This is an article distributed under the terms of the Creative Commons Attribution Non-Commercial No Derivates License (http://creativecommons.org/licenses/by-nc-nd/3.o/), which permits unrestricted use, distribution, and reproduction in any medium, provided the original work is properly cited. 